\title{
Review
}

\section{Novel aspects of Ras proteins biology: regulation and implications}

\author{
Dolores Pérez-Sala ${ }^{1}$ and Angelita Rebollo*,2 \\ ${ }^{1}$ Departamento de Estructura y Función de Proteínas, Centro de Investigaciones \\ Biológicas, CSIC, Velázquez 144, E-28006 Madrid, Spain \\ 2 Department of Immunology and Oncology, Centro Nacional de Biotecnología, \\ Universidad Autónoma, Campus de Cantoblanco, E-28049 Madrid, Spain \\ * corresponding author: Angelita Rebollo, Department of Immunology and \\ Oncology, Centro Nacional de Biotecnología, Universidad Autónoma, Campus \\ de Cantoblanco, E-28049 Madrid, Spain. Tel: (+34-91) 585 4655; fax: (+34-91) \\ 585 4506; email: arebollo@cnb.uam.es
}

Received 14.4.99; revised 16.6.99; accepted 21.6.99

Edited by R. Knight

\begin{abstract}
The importance of Ras proteins as crucial crossroads in cellular signaling pathways has been well established. In spite of the elucidation of the mechanism of RAS activation by growth factors and the delineation of MAP kinase cascades, the overall framework of Ras interactions is far from being complete. Novel regulators of Ras GDP/GTP exchange have been identified that may mediate the activation of Ras in response to changes in intracellular calcium and diacylglycerol. The direct activation of Ras by free radicals such as nitric oxide also suggests potential regulation of Ras function by the cellular redox state. In addition, the array of Ras effectors continues to expand, uncovering links between Ras and other cellular signaling pathways. Ras is emerging as a dual regulator of cellular functions, playing either positive or negative roles in the regulation of proliferation and apoptosis. The signals transmitted by Ras may be modulated by other pathways triggered in parallel, resulting in the final order for proliferation or apoptosis. The diversity of ras-mediated effects may be related in part to differential involvement of Ras homologues in distinct cellular processes. The study of Ras posttranslational modifications has yielded a broad battery of inhibitors that have been envisaged as anti-cancer agents. Although an irreversible modification, Ras isoprenylation appears to be modulated by growth factors and by the activity of the isoprenoid biosynthetic pathway, which may lead to changes in Ras activity.
\end{abstract}

Keywords: Ras proteins; guanine nucleotide exchange; Ras effectors; apoptosis; isoprenylation

Abbreviations: EGF, epidermal growth factor; ERK, extracellular signal-regulated kinase; FTase, farnesyltransferase; GAP, GTPase activating protein; GEF, guanine nucleotide exchange factor; GRF, guanine nucleotide releasing factor; IL-2, interleukin 2; JNK, Jun kinase; MAPK, mitogen-activated protein kinase; NO, nitric oxide; $\mathrm{PH}$, pleckstrin homology; $\mathrm{PI} 3 \mathrm{~K}$, phosphatidylinositol-3-kinase; PPMTase, prenylated protein methyltransferase; SAPK, stressactivated protein kinase

\section{Introduction}

Ras proteins are critical components of signaling pathways that link the activation of cell surface receptors with transcriptional events leading to the control of proliferation, differentiation and apoptosis. The ras genes codes for $21 \mathrm{kDa}$ proteins ( $\mathrm{H}$-Ras, N-Ras, K-Ras4A and K-Ras4B) that function as GDP/GTP-regulated switches ${ }^{1}$ (Figure 1). The two K-Ras forms diverge in the $\mathrm{C}$ terminal as a consequence of alternate exon utilization. Ras proteins are activated transiently in response to diverse extracellular signals such as growth factors, cytokines, hormones and neurotransmitters, which stimulate cell surface receptors. Ras uses several functionally diverse effectors that in turn activate multiple pathways. Several excellent reviews have recently dealt with the topics of Ras-mediated signalling pathways and cross-talk with other low molecular weight GTP-binding proteins. ${ }^{2,3}$ The aim of this article is to survey emerging aspects of Ras protein biology focusing on novel mechanisms of Ras activation, as well as on the involvement of Ras in pro-apoptotic or anti-apoptotic signaling pathways.

\section{Regulation of GDP/GTP exchange}

The activity of Ras proteins is controlled by a cycle between a GDP-bound inactive state and a GTP-bound active state. Although Ras proteins possess intrinsic GTPase exchange activity, it is too low to account for the rapid, transient GDP/ GTP cycling. A complete model for Ras function includes regulatory proteins that control the GTP/GDP cycle, comprising the guanine nucleotide exchange factors (GEF) and the GTPase activating proteins (GAP) (Figure 2). Several GEFs act on Ras, including Sos1 and 2, which couple tyrosine kinase receptors with Ras activation, and GRF1 and 2, which are activated by some $G$ protein-coupled receptors and calcium signals. ${ }^{4}$

Several recent studies have addressed the mechanism of action and regulation of Sos. The solution of the crystal structure of $\mathrm{H}$-Ras coupled to the Ras guanine-nucleotideexchange factor region of Sos ${ }^{5}$ has shown that Sos inserts an $\alpha$-helix into Ras that opens the nucleotide binding site. In turn, Sos activity has been proposed to be regulated by intramolecular interactions. However, the data concerning the role of Sos $\mathrm{N}$ - and $\mathrm{C}$-terminal domains are conflicting; while some studies suggest that both regions exert an inhibitory effect on the activity of the catalytic domain, ${ }^{6}$ 
others propose that the $\mathrm{Dbl}$ and pleckstrin homology $(\mathrm{PH})$ domains of the N-terminal region of Sos are critical for its function. ${ }^{7}$ Sos activity is also regulated by phosphorylation after growth factor stimulation of cells. In addition to MAP kinases ERK1 and 2, it has been recently shown that p90Rsk-2 can phosphorylate Sos. ${ }^{8}$ This phosphorylation is believed to exert a negative feedback effect on Ras stimulation. The observation that Sos activity can be inhibited in vitro by binding of phosphatidylinositol 4,5- $\mathrm{P}_{2}$ $\left(\mathrm{PI} 4,5 \mathrm{P}_{2}\right)$ to the Sos $\mathrm{PH}$ domain ${ }^{9}$ has led to propose that $\mathrm{PI}, 5 \mathrm{P}_{2}$ may serve as a negative regulator of Sos in the cell, and that removal of $\mathrm{PI} 4,5 \mathrm{P}_{2}$ may cause Sos and Ras activation.

The mechanism of GRF activation has not been fully elucidated. GRFs contain cdc25 and Dbl homology regions plus an IQ region, considered the calmodulin (CaM) interaction site. The interaction of GRP with $\mathrm{Ca}^{2+}{ }_{-} \mathrm{CaM}$ leads to GRF activation in intact cells, however, this effect

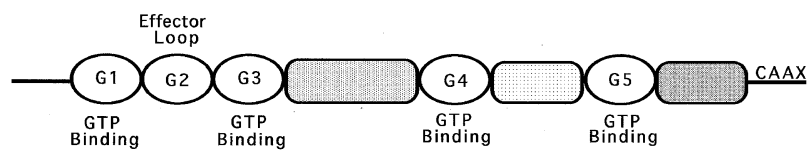

Figure 1 Scheme of Ras showing the GTP-binding sites, which mediate binding and hydrolysis of the guanine nucleotide, the effector loop, which interacts with effector molecules, and the C-terminal CAAX motif does not occur in vitro. ${ }^{10,11}$ It has therefore been proposed that the effect of $\mathrm{Ca}^{2+}$-CaM in vivo may be indirect, modulating the interaction of RasGRF with its targets. ${ }^{10}$ Calcium signals could also contribute to GRF activation by promoting the proteolytic removal of the N-terminal domain, as it has been shown in vitro. ${ }^{11} \mathrm{~A}$ novel member of the family of Ras-GEFs has recently been cloned from brain ${ }^{12}$ and lymphoid tissues. ${ }^{4}$ This factor, named RasGRP, possesses calcium and diacyglycerol-binding domains and may directly couple changes in diacylglycerol and possibly calcium concentrations to Ras activation. The activation of RasGRP ${ }^{4}$ is associated with membrane partitioning of the factor, which suggests that recruitment of RasGRP to membranes may be a primary mechanism for its activation.

GEFs act on $G$ proteins other than Ras, thus functioning as bifunctional signaling proteins that may coordinate the activation of various cellular pathways. Ras GRF1 also serves as a GEF for the Ras-related protein R-Ras, ${ }^{13}$ whereas Ras GRF2 has been reported to bind and activate Rac, thereby coordinating the activation of the ERK and SAPK pathways. ${ }^{10}$ Ras and Rac-activated pathways are also potentially coupled through Sos. ${ }^{14}$

Reactive free radicals and cellular redox stress have been proposed to directly activate Ras. Nitric oxide (NO) promotes the direct posttranslational modification of Ras by single S-nitrosylation at Cys118. This results in stimulation of guanine nucleotide exchange, possibly by destabilization

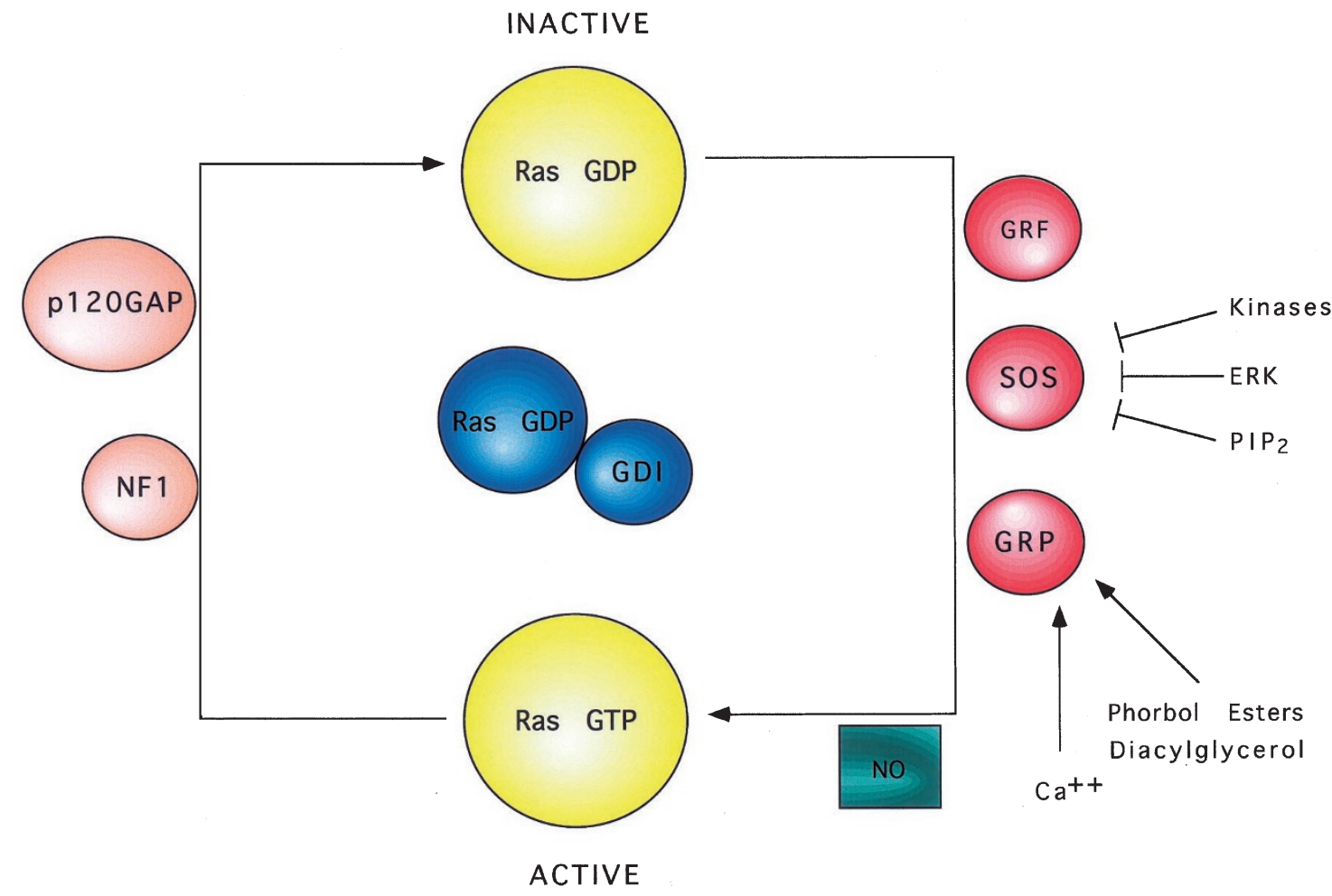

Figure 2 Schematic view of Ras regulatory factors. Ras proteins cycle between the active GTP-bound and the inactive GDP-bound states. Exchange factors (Ras GRF, Sos, GRP) catalyze Ras activation by facilitating the dissociation of bound GDP. Free radicals such as nitric oxide (NO) may also promote Ras-GTP formation. Ras remains active until it hydrolyzes bound GTP to GDP. This process is accelerated by GTPase activating proteins (p120GAP, NF1), which complement the Ras active site 
of the interaction between residues in the GDP-binding pocket and the nucleotide, and leads to activation of downstream signaling. ${ }^{15}$ This suggests that Ras function may be regulated directly by changes in the redox state of the cell and provide a mechanism for the GEF-independent activation of Ras.

The mechanism of action of Ras-GAP has recently been elucidated in a series of biochemical and structural studies, $^{16}$ and will thus be addressed here only briefly. p120 GAP has a C-terminal catalytic domain that contains the Ras-binding domain and interacts with the Ras effector domain. GAP complements the active site of Ras, contributing amino acid residues which are critical for the catalytic process. This represents a unique mechanism for the formation of an active site by the transient association of two different proteins. The $\mathrm{N}$-terminal region of $\mathrm{p} 120$ GAP regulates the catalytic domain and interacts with downstream effectors. In addition to its role as a negative regulator of Ras, p120 GAP acts as a downstream effector of Ras. The Ras GAP NF1 shares sequence identity and substrate specificity with the C-terminal catalytic domain of p120 GAP, and is serine- and threonine-phosphorylated after growth factor stimulation.

Ras GDI represents a third class of proteins that regulate the Ras GTP/GDP cycle. This factor inhibits the dissociation of bound GDP from Ras by preventing the action of GEFs; it does not, however, inhibit GAP action. ${ }^{17}$

\section{Candidate effectors of Ras}

Activated Ras transmits its signal through a wide array of effector proteins. The best characterized Ras effector is the serine/threonine kinase Raf. ${ }^{18}$ Ras/Raf association induces translocation of Raf to the plasma membrane, leading to the activation of its kinase function. After activation, Raf phosphorylates and activates MEK1 and 2 kinases. Activated MEKs are dual threonine and tyrosine kinases that activate ERK1 and 2 kinase, also referred to as MAPKs. Once activated, ERKs translocate to the nucleus, where they phosphorylate and activate a variety of substrates such as the transcription factor Elk1. Constitutively active Raf mutants cause a transformed phenotype and overcome the loss of Ras function caused by a dominant negative Ras mutant. The Raf protein family is composed of three members: Raf-1, A-Raf and B-Raf; B-Raf exists in multiple spliced forms. Ras interacts with two different regions of Raf. The first Ras binding site in Raf is required for translocation, whereas the second is required for full activation. ${ }^{19,20}$ Ras stimulates the kinase activity of Raf only when both molecules interact physically. The mechanism by which Ras enhances Raf activity may be due to the induction of conformation changes in Raf, exposing residues that are substrates for kinases; alternatively, Ras may participate in the assembly of complexes between Raf and other proteins. ${ }^{20}$ The in vitro interaction of Ras and Raf is insufficient to stimulate Raf kinase activity, indicating that other molecules in addition to Ras may be required for Raf activation, such as 14-3-3 proteins and phospholipids. ${ }^{21}$ On the other hand, it has been shown that Raf activation is not required for Ras to induce membrane ruffling, ${ }^{22}$ suggesting that Ras probably associ- ates with other effectors, leading to transduction of Rasmediated signals through multiple pathways.

Among other candidate Ras effectors is phosphatidylinositol-3-kinase (PI3 K). PI3 K is a lipid kinase that phosphorylates phosphoinositides at the $3^{\prime}$ position of the inositol ring. PI3 $\mathrm{K}$ is composed of a p110 catalytic and a p85 regulatory subunit. Multiple PI3 $\mathrm{K}$ isoforms have been isolated and some can associate with Ras. ${ }^{23}$ The PI3 K p110 subunit interacts with Ras-GTP through the domain located between amino acids 133-314. An intact Ras effector domain is essential for this interaction. Mutants in this region show differential impairment of effector interaction, providing information concerning the contribution of Ras effectors to Ras function. ${ }^{24}$

In addition to Raf and PI3 K, other Ras effectors have been proposed, including p120GAP, $\mathrm{PKC} \zeta$, Rin1, AF6, ${ }^{18}$ the GEFs for Ral, RalGDS, Rgl and RIf, ${ }^{25,26}$ and Nore $1 .{ }^{27}$ p120GAP was the first molecule to be proposed as a Ras effector. Although it acts as a negative regulator of Ras, recent evidences suggest novel roles for p120GAP as a Ras effector in the regulation of Rho function and as a bridge that promotes association between Ras and other putative effectors, such as GAP-binding proteins. ${ }^{28}$ Regulatory regions of $\mathrm{PKC} \zeta$ associated with Ras-GTP, suggesting that Ras localizes $\mathrm{PKC} \zeta$ to the plasma membrane, where it may be activated by PtdlnsP3. Yeast studies identified Rin1 as a Ras effector molecule. Rin1 interacts directly with $\mathrm{H}-\mathrm{Ras}$, competes with Raf for binding to Ras in vitro, and forms stable complexes with Ras in vivo. Finally, the Rin1 domain that binds Ras also binds the 14-3-3 protein, suggesting that Rin1 can interact with multiple signaling molecules. AF6 is another Ras effector candidate that was identified by yeast two-hybrid screening. In vitro analysis showed that the AF6 N-terminal domain interacts with Ras-GTP and that this interaction interferes with the binding of Ras to Raf. Ras is able to activate Ral GEFs. It has recently been shown that stimulation of the EGF receptor results in rapid activation of Ral, which correlates with Ras activation and is blocked by dominantnegative Ras. This suggests that Ral activation can be a downstream effect of growth factor-induced Ras activation. ${ }^{26}$ A new Ras effector, called Nore1, has recently been identified by two-hybrid screening. This protein interacts with Ras in vitro in a GTP-dependent manner and the interaction requires an intact Ras effector domain. Ras/ Nore1 association also occurs in vivo following EGF receptor activation. ${ }^{27}$ Another Ras effector candidate is the mitogen-activated protein kinase kinase kinase 1 (MEKK1), a serine/threonine kinase that is an upstream activator of SEK and may serve as a cdc42 and Rac effector as well. ${ }^{29}$ Ras has also been reported to interact with $\mathrm{REKS}^{30}$ and $\mathrm{Bcl}-1,{ }^{31}$ although the physiological role of this association is not yet clear. Finally, using the yeast two-hybrid method, we have shown that Ras interacts with the transcription factor Aiolos. IL-2 deprivation induces Ras/ Aiolos association. One functional consequence of this interaction is the inhibition of the translocation of Aiolos from the cytoplasm to the nucleus. This results in an inhibition of $\mathrm{Bcl}-2$ expression, leading to apoptotic cell death. Our results suggest a novel role for Ras as a blocker 
of $\mathrm{Bcl}-2$ expression through the cytoplasmic sequestration of Aiolos. 32

\section{Anti-apoptotic and pro-apoptotic Ras-mediated signaling pathways}

Ras proteins have been implicated in both protection from and promotion of apoptosis. This apparent contradiction is resolved by the ability of Ras to regulate multiple signaling pathways through interaction with different effector sets. ${ }^{33}$ Ras activation is linked to the cell cycle machinery at several levels. Ras is involved in the regulation of cyclin D1 expression, as evidenced by transient transfection studies employing the cyclin D1 promoter. ${ }^{34}$ Ras also plays a central role in the downregulation of the cdk inhibitor p27/kip, possibly through ERK-catalyzed p27kip phosphorylation, which prevents binding of the inhibitor to cdk2, ${ }^{35}$ and may trigger p27kip degradation by the ubiquitin-proteasome pathway. Ras also mediates the signaling pathway responsible for phosphorylation and activation of the cdc25 phosphoserine phosphatases. To become activated, cdks must be dephosphorylated by the cdc25 phosphates $A, B$ and $C$, all three of which have been found in association with Raf, an interaction that may be facilitated by the 14-3-3 proteins. ${ }^{36}$ c-Myc is involved in transcriptional control of gene expresssion and is essential for cell proliferation; c-myc expression is induced following growth factor stimulation. Using dominant negative and constitutively active Ras mutants, that Ras has been shown to regulate c-Myc expression. ${ }^{37}$ On the other hand, Ras can also mediate anti-proliferative effects. Ras activation can induce p21cip expression and G1 arrest. ${ }^{38}$ In PC12 cells, the extent and duration of Ras activation determines whether cells proliferate or differentiate. Treatment of these cells with EGF leads to transient activation of Ras and proliferation, while stimulation with NGF results in sustained Ras activation, leading to differentiation. The differentiation process is accompanied by a negative regulation of the cell cycle and accumulation of p21 cip. ${ }^{39}$ Oncogenic Ras also causes growth arrest and premature senescence associated with upregulation of p53 and p16ink. ${ }^{40}$ In addition, p19arf is essential for p53 activation in response to oncogenic Ras. ${ }^{41}$

Ras activation has been reported to protect cells from apoptosis induced by various stimuli. The anti-apoptotic activity of Ras has been linked to its ability to activate PI3 $\mathrm{K}$. The PI3 K-mediated survival signal is triggered by the activation of $\mathrm{Akt} / \mathrm{PKB}$, a serine/threonine kinase activated by Ptdlns $-3,4 \mathrm{P}_{2} \cdot{ }^{42}$ There is also evidence, however, that $\mathrm{Akt} / \mathrm{PKB}$ can be activated in a $\mathrm{PI} 3 \mathrm{~K}$-independent fashion, ${ }^{43}$ thus raising the possibility that Akt/PKB-mediated protection from apoptosis can also occur without PI3 K activation. Akt/ $\mathrm{PKB}$ activation is involved in prevention of apoptosis in IL4-stimulated cells, since overexpression of wild type or constitutively active Akt mutants protects cells from IL-4 deprivation-induced apoptosis. Moreover, overexpression of a constitutively active Akt mutant in IL-4-deprived cells correlates with inhibition of JNK2 activity. ${ }^{44}$ Akt/PKB inhibits the activation of caspases, required for the apoptotic response to serum withdrawal. ${ }^{45}$ One mechanism for Akt/ PKB protection against apoptosis is the phosphorylation and inactivation of $\mathrm{Bad}$, a pro-apoptotic $\mathrm{Bcl}-2$ family member. ${ }^{46,47}$ Raf is also able to phosphorylate Bad; phosphorylated Bad does not heterodimerize with $\mathrm{Bcl}-\mathrm{X}_{\mathrm{L}}$, but remains bound to 14-3-3 proteins in the cytoplasm in an inactive form. This suggests that Raf can regulate Bad by a mechanism independent of ERK pathway activation.

The interactions between the Ras and JNK pathways in relation to apoptosis induction are not completely understood. JNK activation may promote different cellular consequences depending on the cell type or on the coordinated activation of other pathways. Activation of JNK has been claimed to be either a trigger or a consequence of apoptosis. IL-2 deprivation correlates with an increase in JNK1 activity directly related to apoptosis induction. ${ }^{48}$ Indeed, downregulation of JNK1 expression inhibits apoptosis induced by IL-2 withdrawal, whereas overexpression of $\mathrm{Bcl}-2$ promotes cell survival and blocks JNK1 activation. This suggests that inhibition of the JNK1 signaling pathway may be a mechanism through which $\mathrm{Bcl}-$ 2 prevents growth factor deprivation-triggered apoptosis. In contrast, activation of the ERK pathway suppresses JNK activity and promotes cell survival. ${ }^{48}$ it has also been shown, however, that inhibition of JNK activation can impair Ras transformation, suggesting a growth-promoting role for this kinase.

Ras activation has also been implicated in apoptosis induction. Ras is reported to mediate signals triggered by activation of the cell death receptor Fas. ${ }^{49}$ Ras activation is also linked to the induction of apoptosis in the phaechromocytoma cell line PC12, which are rescued from apoptosis after expression of a dominant negative Ras mutant. $^{50}$ In T cells, Ras is activated following both IL-2 stimulation and deprivation; this can lead either to cell proliferation or apoptotic cell death, depending on whether other stimuli are acting simultaneously. ${ }^{51,52}$ In this context, the above described interaction between Ras and Aiolos delineates a novel Ras-mediated pro-apoptotic pathway. ${ }^{32}$

Other important targets for Ras signals are the transcription factors NF- $\kappa \mathrm{B}$ and NFAT. NF- $\kappa \mathrm{B}$ is activated in response to many extracellular stimuli and is involved in the regulation of cytokine, chemokine and growth factor genes. ${ }^{53} \mathrm{NF}-\kappa \mathrm{B}$ has been shown to have an anti-apoptotic effect. In NF- $\kappa \mathrm{B}$ deficient cells, as well as in cells expressing a dominant negative $\mid \kappa \mathrm{B} \alpha$, the apoptotic responses to external stimuli are enhanced. ${ }^{54}$ The proposed mechanism for the anti-apoptotic effect of NF$\kappa \mathrm{B}$ is the transcriptional regulation of specific genes that are anti-apoptotic. The ability of activated Ras to transform p53 null cells is dependent on the ability of Ras to activate $\mathrm{NF}-\kappa \mathrm{B}$. There are thus cell death pathways that can be initiated by Ras after the inactivation of $\mathrm{NF}-\kappa \mathrm{B} .{ }^{55}$ Oncogenic $\mathrm{H}$-Ras activates $\mathrm{NF}-\kappa \mathrm{B}$, required for cellular transformation, suggesting that $\mathrm{NF}-\kappa \mathrm{B}$ is a critical downstream mediator of $\mathrm{H}$-Ras signaling. ${ }^{56}$ There is also evidence that in some cell types, NF- $\kappa \mathrm{B}$ can be a proapoptotic molecule. ${ }^{57}$ The finding that some proteins can have a dual role, depending on the cell type and stimuli, demonstrates that integration of signals plays an important role in the induction of proliferation or apoptosis. In parallel with the model proposed for the proto-oncogene c-Myc, it is possible that two different Ras-mediated pathways may be 
triggered by an external stimulus, one involved in proliferation and the other in apoptosis. Alternatively, Ras may simultaneously induce both proliferation and apoptosis, the latter being blocked by the action of survival factors, or Ras may induce either proliferation or apoptosis, depending on external signals.

\section{Homologue-specific roles}

The $\mathrm{H}$-, $\mathrm{N}$ - and K-Ras genes are ubiquitously expressed in mammalian cells. Shortly after their identification, it was realized that mutation of specific Ras homologues is associated with different tumor types. ${ }^{1}$ Much of the effort in Ras research in past years has been devoted to the identification of Ras effectors and to the delineation of the signaling pathways in which these proteins are crucial crosspoints. However, during this time, less attention has been paid to potentially different behavior and/or Ras genes involvement in distinct signaling processes. A number of recent works suggest that the different Ras homologues may preferentially mediate distinct cellular processes. K-Ras, but not $\mathrm{H}$ - or $\mathrm{N}$ Ras, plays an essential role in murine development. ${ }^{57,58}$ In keeping with this, $\mathrm{K}$ - but not $\mathrm{H}$-Ras interacts specifically with microtubules, ${ }^{59}$ and oncogenic $\mathrm{K}$ - but not $\mathrm{H}$-Ras disrupts basolateral polarity in colon epithelial cells. ${ }^{60}$ Selective activation of $\mathrm{H}$-Ras by Ras-GRF has recently been reported, suggesting the potential participation of each of the Ras homologues in different signaling pathways. ${ }^{61}$ This hypothesis is supported by recent findings that unveil a differential ability of the four Ras homologues to induce focus formation, cell migration or anchorage-dependent cell growth. ${ }^{62}$ Interestingly, it has been found that Ras homologues vary in their ability to activate the key effectors Raf- 1 and phosphoinoside 3-kinase, ${ }^{63}$ with K-Ras more effective as a recruiter and activator of Raf- 1 and $\mathrm{H}$-Ras more effective as a PI3 $\mathrm{K}$ activator. The activation of these two effectors has been related with either induction or protection from apoptosis, respectively. ${ }^{33}$ In this context, results from our laboratory have evidenced distinct behavior for Ras homologues in cells undergoing apoptosis in response to interleukin-2 withdrawal; K-Ras is present in mitochondria only in IL-2-supplemented cells, and H-Ras is observed in mitochondria only following IL-2 withdrawal. ${ }^{64}$ Taken together, these observations suggest that each Ras protein may mediate significantly different biological processes. The picture of Ras signaling may thus offer a different view once homologue-specific studies have been conducted.

\section{Ras posttranslational modifications}

Ras proteins are modified by farnesylation, C-terminal proteolysis and methylation. In addition, $\mathrm{H}$ - and $\mathrm{N}$-Ras proteins can be reversibly palmitoylated. The observation that C-terminal modification is important for Ras-mediated transformation, spurred research on the enzymology of these processes. ${ }^{65,66}$ In fact, the various activities participating in Ras C-terminal processing have been marked as targets for the design of antiproliferative drugs. An extensive battery of substrates and inhibitors of Ras-modifying enzymes has become available in recent years, and has helped unveil unpredicted aspects of Ras regulation. The three Ras homologues differ widely in their susceptibility to inhibition of farnesyltransferase (FTase). H-Ras is uniquely sensitive FTase inhibitors and K-Ras is highly resistant to inhibition, due to its ability to be alternatively modified by geranylgeranyl in cells treated with FTase inhibitors. ${ }^{67,68}$ Pharmacological and genetic tools have made it possible to ascertain that Ras posttranslational modifications are necessary for Ras interaction with both regulators and effectors. ${ }^{69}$ Novel mechanisms for regulation of Ras processing have recently been proposed. Induction of the cholesterol/isoprenoid biosynthetic pathway by lipoprotein depletion can upregulate the farnesylation and membrane association of Ras, an effect associated with Ras-driven changes in muscarinic receptor and $\mathrm{G}$ protein expression. ${ }^{70}$ Conversely, cholesterol enrichment may lead to a reduction in Ras farnesylation and membrane association, and decreased MAP kinase activity. ${ }^{71}$ On the other hand, the modification of Ras posttranslational status may contribute to the potentiation of growth factorinduced DNA synthesis by insulin; it has been shown that insulin can activate FTase, apparently by a phosphorylationdependent process, and augment levels of farnesylated Ras. $^{72}$ Moreover, FTase amplifies growth-factor mediated proliferation and transformation of NIH 3 T3 cells. ${ }^{73}$ Farnesylation of Ras proteins is necessary for proteolysis and carboxylmethylation. The most intensive research has thus been done in the area of prenyltransferase enzymes, and has led to the solution of the FTase crystal structure. ${ }^{74}$ Inhibition of the latter processes is not without consequences, however, as disruption of Ras $\mathrm{C}$ terminus proteolytic processing leads to defects in Ras localization and signaling, and suppresses the activated phenotype associated with the allele RAS2val19 in yeast. ${ }^{75}$ Recently-conducted studies in yeast have led to the identification of two gene products, Ste $24 p$ and Rce1p, which partially overlap as C-terminal CAAX proteases. ${ }^{75,76}$ The human homologue of Ste24p has been recently cloned, and it appears that this protease can mediate multiple types of proteolytic events. ${ }^{77}$ In addition, disruption of the mouse Rce1 gene results in defective Ras processing and mislocalization. ${ }^{78}$ The CAAX methyltransferase family also comprises functional homologues, as deduced from cross-species complementation studies. ${ }^{79}$ It has recently been reported that homocysteine, the levels of which are increased in patients with high risk of myocardial infarction and stroke, can act as an endogenous methyltransferase inhibitor due to its ability to increase intracellular S-adenosyl-homocysteine levels in endothelial cells. This effect is accompanied by a marked reduction in Ras methylation, as well as membrane association and MAP kinase activation. ${ }^{80}$ Farnesyl-based inhibitors of prenylated protein methyltransferase (PPMTase) inhibit Ras-dependent cell growth ${ }^{81}$ and impair various G protein-dependent processes; ${ }^{65}$ it appears, however, that not all effects of these molecules can be attributed to PPMTase inhibition. ${ }^{82}$ It should also be taken into account that, just as FTase inhibitors can target proteins other than Ras, including Rho $B$, nuclear lamins $A$ and $B, T C 21$ or Rheb, ${ }^{83}$ the prenylbased PPMTase inhibitors can target an even wider array of cellular proteins. ${ }^{84}$ Care must therefore be exercised when attributing the effects of these inhibitors to the blockade of Ras function. Ras palmitoylation also requires prior farnesyl 
attachment. The distinct contributions of these two lipid modifications to Ras function have been recently explored using non-farnesylated C-terminal mutants of $\mathrm{H}$-Ras. ${ }^{85}$ These mutants can be palmitoylated and trigger differentiation and transformation, suggesting that palmitate can support $\mathrm{H}$-Ras membrane binding and two different biological functions. ${ }^{85}$

\section{References}

1. Barbacid M (1987) Ras genes. Ann. Rev. Biochem. 56: 779-827

2. Hall A (1998) G proteins and small GTPases: distant relatives keep in touch. Science 279: $509-514$

3. Bos JL (1998) All in the family? New insights and questions regarding interconnectivity of Ras, Rap1 and Ral. EMBO J. 17: 6776-6782

4. Tognon CE, Kirk HE, Passmore LA, Whitehead IP, Der CJ and Kay RJ (1998) Regulation of Ras GRP via phorbol ester-responsive C1 domain. Mol. Cell. Biol. 18: $6995-7008$

5. Boriack-Sjodin PA, Margarit SM, Bar-Sagi D and Kuriyan J (1998) The structural basis of the activation of Ras by Sos. Nature 394: $337-343$

6. Corbalan-Garcia S, Margarit SM, Galron D, Yang SS and Bar-Sagi D (1998) Regulation of Sos activity by intermolecular interactions. Mol. Cell. Biol. 18: $880-886$

7. Qian X, Vass WC, Papageorge AG, Anborgh PH and Lowry DR (1998) Nterminus of Sos1 Ras exchange factor: critical role for the Dbl and PH domains. Mol. Cell. Biol. 18: $771-778$

8. Douville E and Downward J (1997) EGF-induced Sos phosphorylation in PC12 cells involves p90 RSK2. Ras signalling and apoptosis. Oncogene 15: $373-383$

9. Jefferson AB, Klippel A and Williams LT (1998) Inhibition of mSos activity by binding of PIP2 to the mSos PH domain. Oncogene 16: 2303-2310

10. Fan WT, Koch CA, Hoog CLD, Fam NP and Moran MF (1998) The exchange factor Ras-GRF2 activates Ras-dependent and Rac-dependent MAP kinase pathways. Curr. Biol. 8: 935-938

11. Baouz S, JacquetE, Bernardi A and Parmeggiani A (1997) The N terminal motif of cdc25, a GDP/GTP exchange factor for Ras, controls the activity of the catalytic domain. Modulation by calmodulin and calpain. J. Biol. Chem. 272: 6671-6676

12. Ebinu JO, Bottorff DA, Chan EYW, Stang SL, Dunn RJ and Stone JC (1998) RasGRP, a ras guanyl nucleotide-releasing protein with calcium- and diacylglycerol-binding motifs. Science 280: 1082-1086

13. Gotoh T, Niino Y, Tokuda M, Hatase O, Nakamura S, Matsuda M and Hattori S (1997) Activation of R-Ras by Ras guanine nucleotide releasing factor. J. Biol. Chem. 272: $18602-18607$

14. Nimnual AS, Yatsula BA and Bar-Sagi D (1998) Coupling Ras and Rac through the Ras exchange factor Sos. Science 279: 560-563

15. Lander HM, Hajjar DP, Hempstead BL, Mirza UA, Chait BT, Campbell S and Quilliam LA (1997) A molecular redox switch on p21ras. Structural basis for the nitric oxide-p21 ras interaction. J. Biol. Chem. 272: 4323-4326

16. Scheffzek K, Ahmadian MR and Wittinghofer A (1998) GTPase-activating proteins: helping hands to complement an active site. Trends Biochem. Sci. 23: 257-262

17. Nakanishi H, Kaibuchi K, Orita S, Ueno N and Takai Y (1996) Different functions of Smg GDP dissociation stimulator and mammalian counterpart of cdc25. J. Biol. Chem. 269: 15085-15091

18. Campbell SL, Khosravi-Far R, Rossman KL, Clark GJ and Der CJ (1998) Increasing complexiity of Ras signalling. Oncogene 17: 1395-1413

19. Roy S, Lane A, Yan J, McPherson R and Hancock JF (1997) Activity of plasma membrane recruited Raf-1 is regulated by Ras via the Raf zinc finger. J. Biol. Chem. 272: 20139-20145

20. Mineo C, Anderson RG and White M (1997) Physical association with Ras enhances activation of membrane-bound Raf (Raf-CAAX). J. Biol. Chem. 272: $10345-10348$

21. Morrison DK and Cutler RE (1997) The complexity of Raf regulation. Curr. Opin. Cell. Biol. 9: 174-179

22. Symons M (1996) Rho family of GTPases: the cytoskeleton and beyond. Trends Biochem. Sci. 21: 178-181
23. Rodríguez-Viciana $\mathrm{P}$, Warne $\mathrm{PH}$, Khwaja A, Marte BM, Pappin D, Das P, Waterfield MD, Ridley A and Downward J (1997) Role of PI3 kinase in cell transformation and control of the actin cytoskeleton by Ras. Cell 89: 457-467

24. Winkler DG, Johnson JC, Cooper JA and Vojtek AB (1997) Identification and characterization of mutations in $\mathrm{H}$-Ras that selectively decrease binding to Raf1. J. Biol. Chem. 272: 24402-24409

25. Feig LA, Urano T and Cantor S (1996) Evidence for Ras/Ral signal cascade. Trends Biochem. Sci. 21: 438-441

26. Wolthuis RM, Zwartkruis F, Moen TC and Bos JL (1998) Ras-dependent activation of the small GTPase Ral. Curr. Biol. 8: 471-474

27. Vavvas D, Li X, Avruch J and Zhang XF (1998) Identification of Nore1 as a potential ras effector. J. Biol. Chem. 273: 5439-5442

28. Tocque B, Delumeau I, Parker F, Maurier F, Multon MC and Schweighoffer F (1997) Ras-GTPase activating protein: a putative effector for ras. Cell Signal 9: $153-158$

29. Fanger GR, Johnson NJ and Johnson GL (1997) MEK kinases are regulated by EGF and selectively interact with Rac/cdc42. EMBO J. 16: 4961-4972

30. Shimizyu K, Kuroda S and Matsuda S (1994) Synergistic activation by Ras and 14-3-3 protein of a MAPKKK named Ras-dependent extracellular signalregulated kinase kinase stimulator. J. Biol. Chem. 269: 31706-31710

31. Chen CY and Faller DV (1996) Phosphorylation of Bcl-2 protein and association with p21ras in ras-induced apoptosis. J. Biol. Chem. 271: 2376-2379

32. Romero F, Martínez-A C, Camonis J and Rebollo A (1999) Aiolos transcription factor controls cell death in T cells by regulating $\mathrm{Bcl}-2$ expression and its cellular localization. EMBO J. 18: 3719-3730

33. Downward J (1998) Ras signaling and apoptosis. Curr. Opin. Gen. Dev. 8: 4954

34. Arber N, SutterT, Miyake M, Kahn SM, Vekatraj VS, Sobrino A, Warburton D, Holt PR and Weinstein IB (1996) Increased expression of cyclin D1 and the Rb tumor suppressor gene in K-Ras transformed rat enterocytes. Oncogene 12: $1903-$ 1908

35. Kawada M, Yamagoe S, Murakina Y, Suzuki K, Mizuno S and Uehara Y (1997) Induction of p27kip degradation and anchorage independence by Ras through the MAP kinase signalling pathway. Oncogene 15: 629-637

36. Conklin DS, Galaktionov K and Beach D (1995) 14-3-3 protein associates with cdc25 phosphatases. Proc. Natl. Acad. Sci. USA 92: 7892-7896

37. Kerkhoff E and Rapp UR (1998) High intensity Raf signals converts mitotic cell cycling into cellular growth. Cancer Res. 58: 1636-1640

38. Woods D, Parry D, Cherwinski H, Bosch E, Lees E and McMahon M (1997) Raf induced proliferation or cell cycle arrest is determined by the level of Raf activity with arrest mediated by p21cip. Mol. Cell. Biol. 17: 5598-5611

39. Yan GZ and ZiffEB (1995) NGF regulates the PC12 cell cycle machinery through specific inhibition of cdk kinases and induction of cyclin D1. J. Neurosci. 15: 6200-6212

40. Serrano M, Lian AW, McCurrach ME, Beach D and Lowe SW (1997) Oncogenic Ras provokes premature senescence associated with accumulation of p53 and p16ink4A. Cell 88: 593-602

41. Palmero I, Pantoja $C$ and Serrano M (1998) p19arf links the tumor suppressor p53 to Ras. Nature 395: 125-126

42. Franke TF, Kaplan DR and Cantley LC (1997) PI3K: downstream AKTion blocks apoptosis. Cell 88: 435-437

43. KonishiH, Matsuzaki H, Tanaka M, Ono Y, Tokunaga C, Kuroda Sand KikkawaU (1996) Activation of Rac protein kinase by heat shock and hyperosmolarity stress through a pathway independent of PI3K. Proc. Natl. Acad. Sci. USA 93: 7639 7643

44. Cerezo A, Martínez-A C, Lanzarot D, Fischer S, Franke T and Rebollo A (1998) Role of Akt and JNK2 in apoptosis induced by IL-4 deprivation. Mol. Biol. Cell. 8: 3107-3118

45. Kennedy SG, Wagner AJ, Conzen SD, Jordan J, Bellascosa A, Tsichlis PN and Hay N (1997) The PI3K/Akt signaling pathway delivers an anti-apoptotic signal. Genes Dev. 11: 701-713

46. Peso LD, Gonzalez M, Page C, Herrera R and Nuñez G (1997) IL-3 induces phosphorylation of bad through protein kinase Akt. Science 278: 687-689

47. Datt S, Dudek H, Tao X, Masters S, Fu H, Gotoh Y and Greenberg ME (1997) Akt phosphorylation of $B A D$ couples cell survival signals to cell-intrinsic death machinery. Cell 91: 231-241

48. Cerezo A, Martínez-A C, Gómez J and Rebollo A (1999) IL-2 deprivation triggers apoptosis which is mediated by $\mathrm{c}$-Jun $\mathrm{N}$-terminal kinase 1 activation and prevented by $\mathrm{Bcl}-2$. Cell Death Differ. 6: $87-94$ 
49. Gulbins E, Bissonett R and Mahbouhi A (1995) Fas-induced apoptosis is mediated via ceramide-initiated Ras signaling pathway. Immunity 2: 341-351

50. Ferrari $G$ and Green LA (1994) Proliferative inhibition by dominant negative Ras rescues naive and neuronally differentiated $\mathrm{PC} 12$ cells from apoptotic death. EMBO J. 13: $5922-5928$

51. GómezJ, Martínez-AC, Fernández B, García A and Rebollo A(1996)Critical role of Ras in proliferation and prevention of apoptosis mediated by IL-2. J. Immunol 157: $2272-2281$

52. Gómez J, Martínez-A C, Fernández B, García A and Rebollo A (1997) Ras activation leads to cell proliferation or apoptotic cell death upon IL-2 stimulation or lymphokine deprivation, respectively. Eur. J. Immunol. 27: 1610-1618

53. Bauerle PA and Baltimore D (1996) NF- $\kappa$ B: Ten years after. Cell $87: 13-20$

54. Beg AA and Baltimore D (1996) An essential role of NF- $\kappa$ B in prevention of TNF $\alpha$ induced cell death. Science 274: 782-784

55. Mayo MW, Wang CY, Cogswell PC, Rogers-Graham KS, Lowe SW, Der CJ and Baldwin AS (1997) Requirement of NF- $\kappa$ B activation to suppress p53independent apoptosis induced by oncogenic Ras. Science 278: 1812-1815

56. Finco TS, Westwick JK, Norris JL, Bewg AA, Der CJ and Baldwin AS (1997) Oncogenic $\mathrm{H}$-Ras-induced signaling activates NF- $\kappa$ B transcriptional activity, which is required for cellular transformation. J. Biol. Chem. 272: 24113-24116

57. Koera K, Nakamura K, Nakao K, Miyoshi J, Tokoshima K, Hatta T, Otani H, Aiba A and Katsiki M (1997) K-Ras is essential for development of mouse embryo. Oncogene 15: $1151-1159$

58. Johnson L (1997) K-Ras is an essential gene in the mouse with partial functional overlapping with N-Ras. Genes Dev. 11: 2468-2481

59. Thissen JA, Gross JM, Subramanian K, Meyer T and Casey PJ (1997) Prenylation-dependent association of Ki-Ras with microtubules. Evidence for a role in subcellular trafficking. J. Biol. Chem. 272: 30362-30370

60. Yan Z, Deng X, Chen M, Xu Y, Ahram M, Sloane BF and Friedman E (1997) Oncogenic K-Ras, but not oncogenic $\mathrm{H}$-Ras upregulates CEA expression and disrupts basolateral polarity in colon epithelial cells. J. Biol. Chem. 272: 27902 27907

61. Jones MK and Jackson JH (1998) Ras-GRF activates H-Ras, but not N-Ras or K-Ras4B protein in vivo. J. Biol. Chem. 273: 1782-1787

62. Voice JK, Klemke RL, Le A and Jackson JH (1999) Four human Ras homologs differ in their abilities to activate Raf-1, induce transformation and stimulate cell motility. J. Biol. Chem. 274: 17164-17170

63. Yan J, Roy S, Apolloni A, Lane A and Hancock JF (1998) Ras isoforms vary in their ability to activate Raf-1 and PI3 kinase. J. Biol. Chem. 273: 24052-24056

64. Rebollo A, Pérez-Sala D and Martinez-A C (1999) Bcl-2 differentially targets K$\mathrm{N}$ - and $\mathrm{H}$-Ras to mitochondria in IL-2 supplemented cells: Implications in prevention of apoptosis. Oncogene, in press

65. Zhang FL and Casey PJ (1996) Protein prenylation: molecular mechanisms and functional consequences. Ann. Rev. Biochem. 65: 241-269

66. Ashby MN (1998) CAAX converting enzymes. Curr. Opin. Lipidol. 9: 99-102

67. Whyte DB, Kirschmeier P, Hockenberry TN, Nunez-Oliva I, James L, Catino JJ, Bishop WR and Pai JK (1997) K-Ras and N-Ras are geranylgeranylated in cells treated with farnesyl protein transferase inhibitors. J. Biol. Chem. 272: 1445914464

68. Lerner EC, Zhang TT, Knowles DB, Qian Y, Hamilton AD and Sebti SM (1997) Inhibition of the prenylation of $\mathrm{K}$-Ras, but not $\mathrm{H}$ - or $\mathrm{N}$-Ras, is highly resistant to CAAX peptidomimetics and requires both a farnesyltransferase and a geranylgeranyltransferase I inhibitor in human tumor cell lines. Oncogene 15: $1283-1288$
69. Geyer M and Wittinghofer A (1997) Structure of the Ras binding domain of RaIGEF and implications for Ras binding and signalling. Curr. Opin. Struct. Biol. 7: $786-792$

70. Gadbut AP, Wu L, Tang D, Papageorge A, Watson JA and Galper JB (1997) Induction of the cholesterol metabolic pathway regulates the farnesylation of Ras in embryonic chick heart cells: a new role for Ras in regulating the expression of muscarinic receptors and G proteins. EMBO J.16: 7250-7260

71. Pomerantz KB, Lander HM, Summers B, Robishaw JD, Balcueva E and Hajjar DP (1997) G protein-mediated signaling in cholesterol-enriched arterial smooth muscle cells. Role of PKC-delta in the regulation of eicosanoid production. Biochemistry 36: 9523-9531

72. Goalstone ML, Leitner JW, Wall K, Dolgonos L, Rother KI, Accili D and Draznin B (1998) Effect of insulin on farnesyltransferase. Specificity of insulin action and potentiation of nuclear effects of insulin-like growth factor 1, epidermal growth factor and platelet-derived growth factor. J. Biol. Chem. 273: 23892-23896

73. Nagase T, KawataS, Nakajima H, Tamura S, Yamasaki E, FukuiK, YamamotoK, Miyagawa J, Matsumura I, Matsuda Y and Matsuzawa Y (1999) Effect of farnesyltransferase overexpression on cell growth and transformation. Int. J. Cancer 80: 126-133

74. Park HW, Boduluri SR, Moomaw JF, Casey PJ and Beese LS (1997) Crystal structure of protein farnesltransferase at $2.25 \AA$ resolution. Science $275: 1800$ 1804

75. Boyartchuk VL, Ashby MN and Rine J (1997) Modulation of Ras and a-factor by carboxyl-terminal proteolysis. Science 275: 1796-1800

76. Otto JC, KimE, Young SG and Casey PJ (1999) Cloning and characterization of a mammalian prenyl protein-specific protease. J. Biol. Chem. 274: 8379-8382

77. Tam A, Nouvet FJ, Kamada KF, Slunt H, Sisodia SS and Michaelis S (1998) Dual roles of Ste24p in yeast a-factor maturation: $\mathrm{NH}_{2}$ proteolysis and $\mathrm{COOH}$-terminal CAAX processing. J. Cell Biol. 142: 635-649

78. Kim E, Ambroziak P, Otto JC, Taylor B, Ashby M, Shannon K, Casey PJ and Young SG (1999) Disruption of the mouse Rce1 gene results in defective Ras processing and mislocalization of Ras within cells. J. Biol. Chem. 274: 83838390

79. Romano JD, Schmidt WK and Michaelis S (1998) The S. cerevisiae prenylcysteine carboxy methyltranferase Ste14p is in the endoplasmic reticulum membrane. Mol. Biol. Cell 9: 2231-2247

80. Wang H, Yoshizumi M, Lai K, Tsai JC, Perrella MA, Haber E and Lee ME (1997) Inhibition of growth and Ras methylation in vascular endothelial cells by homocysteine, but not cysteine. J. Biol. Chem. 272: 25380-25385

81. Marom M, Haklai R, Ben-Baruch G, Marciano D, Egozi Y and Kloog Y (1995) Selective inhibition of Ras-dependent cell growth by farnesylthiosalicylic acid. J. Biol. Chem. 270: 22263-22270

82. Pérez-Sala D, Gilbert BA, Rando RR and Cañada FJ (1998) Analogs of farnesylcysteine induce apoptosis in HL60 cells. FEBS Lett. 426: 319-324

83. CoxAD and Der CJ (1997) Farnesyl transferase inhibitors and cancer treatment: targeting simply Ras? Biochim. Biophys. Acta. 1333: F51-F71

84. Rando RR (1996) Chemical biology of protein isoprenylation/methylation. Biochim. Biophys. Acta 1300: 5-16

85. Booden MA, Baker TL, Solski PA, Der CJ, Punke SG and Buss JE (1999) A non farnesylated $\mathrm{H}$-Ras protein can be palmitoylated and trigger potent differentiation and transformation. J. Biol. Chem. 274: 1423-1431 